\title{
Predicting skilled delivery service use in Ethiopia: dual application of logistic regression and machine learning algorithms
}

\author{
Brook Tesfaye $^{1^{*}}$ (D), Suleman Atique ${ }^{2,3}$, Tariq Azim ${ }^{4}$ and Mihiretu M. Kebede $e^{5,6,7}$
}

\begin{abstract}
Background: Skilled assistance during childbirth is essential to reduce maternal deaths. However, in Ethiopia, which is among the six countries contributing to more than half of the global maternal deaths, the coverage of births attended by skilled health personnel remains very low. The aim of this study was to identify determinants and develop a predictive model for skilled delivery service use in Ethiopia by applying logistic regression and machine-learning techniques.

Methods: Data from the 2016 Ethiopian Demographic and Health Survey (EDHS) was used for this study. Statistical Package for Social Sciences (SPSS) and Waikato Environment for Knowledge Analysis (WEKA) tools were used for logistic regression and model building respectively. Classification algorithms namely J48, Naïve Bayes, Support Vector Machine (SVM), and Artificial Neural Network (ANN) were used for model development. The validation of the predictive models was assessed using accuracy, sensitivity, specificity, and area under Receiver Operating Characteristics (ROC) curve.

Results: Only 27.7\% women received skilled delivery assistance in Ethiopia. First antenatal care (ANC) [AOR $=1.83,95 \%$ $\mathrm{Cl}(1.24-2.69)]$, birth order $[\mathrm{AOR}=0.22,95 \% \mathrm{Cl}(0.11-0.46)]$, television ownership $[\mathrm{AOR}=6.83,95 \% \mathrm{Cl}(2.52-18.52)]$, contraceptive use $[\mathrm{AOR}=1.92,95 \% \mathrm{Cl}(1.26-2.97)]$, cost needed for healthcare $[\mathrm{AOR}=2.17,95 \% \mathrm{Cl}(1.47-3.21)]$, age at first birth $[A O R=1.96,95 \% \mathrm{Cl}(1.31-2.94)]$, and age at first sex $[A O R=2.72,95 \% \mathrm{Cl}(1.55-4.76)]$ were determinants for utilizing skilled delivery services during the childbirth. Predictive models were developed and the $\mathbf{4} 48$ model had superior predictive accuracy (98\%), sensitivity (96\%), specificity (99\%) and, the area under ROC (98\%).

Conclusions: First ANC and contraceptive uses were among the determinants of utilization of skilled delivery services. A predictive model was developed to forecast the likelihood of a pregnant woman seeking skilled delivery assistance; therefore, the predictive model can help to decide targeted interventions for a pregnant woman to ensure skilled assistance at childbirth. The model developed through the J48 algorithm has better predictive accuracy. Web-based application can be build based on results of this study.
\end{abstract}

Keywords: Skilled delivery, Machine learning

\footnotetext{
* Correspondence: balagerusew7@gmail.com

${ }^{1}$ World Health Organization, Kenya Country Representative Office, United

Nations Office in Nairobi (UNON), Gigiri Complex, Block "U", Nairobi, Kenya

Full list of author information is available at the end of the article
}

(c) The Author(s). 2019 Open Access This article is distributed under the terms of the Creative Commons Attribution 4.0 International License (http://creativecommons.org/licenses/by/4.0/) which permits unrestricted use, distribution, and reproduction in any medium, provided you give appropriate credit to the original author(s) and the source, provide a link to the Creative Commons license, and indicate if changes were made. The Creative Commons Public Domain Dedication waiver (http://creativecommons.org/publicdomain/zero/1.0/) applies to the data made available in this article, unless otherwise stated. 


\section{Background}

Reducing the global Maternal Mortality Ratio (MMR) to less than 70 deaths per 100,000 births is one of the targets of the Sustainable Development Goals (SDGs). In addition, a secondary objective of this goal is to have no country with a MMR more than twice the global average [1]. However, maternal mortality persists to be high; with about 830 women dying due to complications during and following pregnancy and childbirth each day. In 2015, an estimated 303,000 women died due to maternal causes, with $99 \%$ of these deaths, most of which could have been averted, occurring in developing countries [2, 3]. Major complications that account for nearly $75 \%$ of all maternal deaths are obstructed labor, ruptured uterus, severe pre-eclampsia/ eclampsia, malaria and, complications from abortion [4-7].

Skilled care before, during, and after childbirth can save the lives of both women and newborns $[8,9]$. The highest number of maternal deaths occurs due to complications on the first $24 \mathrm{~h}$ after childbirth, indicating the importance of quality care during early postnatal period [10-16]. Most of these complications, and thus significant number of maternal mortalities and morbidities, could have been prevented with the presence of a skilled birth attendant at the time of childbirth [12, 14, 17].

More than half of the global maternal deaths occurred in high-burden countries, Ethiopia being one of them with an estimated MMR of 412 per 100,000 live births [3, 18-20]. Home delivery, without the presence of a skilled birth attendant (defined as a midwife, trained nurse, doctor, or a health extension worker/community health worker) is unacceptably high in Ethiopia [20, 21] . Skilled delivery is one of the most monitored indicators of the Millennium Development Goals (MDGs). Skilled assistance before, during, and after childbirth could avert up to three-quarter or more of maternal deaths [22, 23]. However, coverage of skilled delivery remained low, although rapid expansion of health facilities and trained human resources are being improved. In Ethiopia, the proportion of births attended by Skilled Birth Attendance (SBA) in 2000, 2005, 2011 and 2016 was about 6.0, $5.7,10.0$, and $27.7 \%$ respectively [20]. Various determinants that influence skilled delivery service use or delivery at home have been well studied [24]. Knowledge from these studies can be applied to develop models that can help to predict the likelihood of a woman using skilled delivery services, and thereby, can help to target specific interventions for that woman to ensure that she is provided skilled services during childbirth.

Machine-learning is a novel method of analyzing big databases, exploring meaningful information and developing models for prediction, clustering and associations [25-28]. Machine-learning algorithms are methodologies used for big data analytics. These algorithms make data mining capable of mining information that commonly used statistical methods (logistic regression) fail to present. While statistical methods only quantify data, data mining develops models to identify hidden patterns and relationships in the data, usually from large volumes of database. Machinelearning is a widely used method in computing which is becoming popular in medicine and public health as well [29]. Large number of studies have identified predictors of skilled delivery service use. However, they fail to present information that is unknown in advance. Applying data mining techniques is different from commonly used statistical methods (for example logistic regression) as it extracts valuable information on the absence of any clear hypothesis [30]. Furthermore, large volumes of quality data, such as DHS, are being collected and recorded in the health sector. There is a growing need of applying better analytical techniques on those voluminous data to extract evidences that improve decisions in the health sector. In this study, we aimed to assess determinants of skilled delivery use by applying a reliable predictive model using machine-learning methods.

\section{Methods}

\section{Study setting, design and period}

The study was conducted in Ethiopia from May to December 2018. A secondary data analysis was applied using data from the recent Ethiopian Demographic and Health Survey (EDHS) of 2016.

\section{Study population}

Women in the reproductive age group (aged 15 to 49 years) who gave at least one live birth in the last five years preceding the survey were included in this study.

\section{Study design and sampling techniques}

For EDHS 2016, 18,008 households were sampled and the survey was implemented in 17,067 households. From these households 16,583 eligible women were interviewed with response rate of $94.2 \%$. Of these women, 11 , 023 women belong to the age group 15-49 years, and had given at least one birth in the last five years preceding the survey.

\section{Data collection instruments and procedures}

Data on the utilization of skilled delivery services and associated characteristics was collected from the study population administering a Demographic and Health Surveys (DHS) standardized women's questionnaire [31]. However, if the woman had more than one child in the last five years preceding the survey, information on the use of skilled assistance during delivery was collected for the last birth [31-33]. 


\section{Data analysis and presentations}

Data cleaning was performed to prepare the dataset for analysis based on objectives of the study.

Study variables were re-coded to meet the desired classification. To overcome unbalanced distribution of samples [34] and ensure representativeness of survey results at national level [35], sampling weights were used during analysis. Twenty-seven records $(0.24 \%)$ with missing values were excluded from the analysis to improve the quality of predictive models being developed. Statistical Package for Social Sciences (SPSS) for Windows version 23.0 software was used for the analysis. Descriptive statistics was carried out to describe women's characteristics. Bivariate analysis was conducted to investigate association of dependent and independent variables. All variables that show a statistically significant association $(p<0.05)$ on bivariate analysis were entered into multivariable logistic regression analysis to control the effect of confounding factors. To estimate the effect of the independent variables on the dependent variable, Odds Ratio (OR) with its 95\% Confidence Interval (CI) were computed.

\section{Predictive modeling}

Predictive model development was based on variables that were found significant in the multivariable logistic regression analysis. Data about the study population based on those variables was extracted. Waikato Environment for Knowledge Analysis (WEKA) for Windows version 3.8.1 software was utilized to conduct the predictive modelling.

Classification method of machine learning was performed by organizing the data in given classes [36]. This classification method, known as supervised classification, uses given class labels to order the objects in the data collection where all objects are already associated with known class labels. The classification algorithm learns from the training dataset and builds a model, which is used to classify new objects, known as test dataset [37]. Synthetic Minority Oversampling Technique (SMOTE) was applied to balance the dataset and minimize sampling errors [36]. Information-gain attribute selection method in WEKA [36] was applied to rank attributes having strong association with skilled delivery. This helped to classify the database and developing models with highest accuracy possible. As a result, seven attributes identified from the multivariable logistic regression analysis (Table 2) were considered for developing predictive model.

Estimating performance of classifiers, a stratified ten-fold cross-validation approach, was used. Empirical studies exhibited that the ten-fold cross-validation seem to be an optimal number of folds (that optimizes the time it takes to complete the test while minimizing the bias and variance associated with the validation process) [38, 39]. In the ten-fold crossvalidation, the entire dataset was divided into ten mutually exclusive folds with approximately the same class distribution as the original dataset. Each fold was used once to test the performance of the classifier that is generated from the combined data of the remaining nine folds, leading to ten independent performance estimates.

The dataset was randomly categorized into two groups, training and test groups. The training group comprised of 9920 cases (90\% of the whole dataset). The prediction model was developed relying on the training group. The remaining 1103 cases (10\% of the whole dataset) were allocated as the test group for model evaluation [40]. Model training was conducted frequently. Since a large sample was undertaken, 90/10\% split rule was applied for model development and testing [41].

In this study, four classification algorithms namely Naïve Bayes, J48, Artificial Neural Network (ANN), and Support Vector Machine (SVM) classification algorithms in WEKA were employed. Accordingly, in line with maternal health domain expert's recommendation, the study developed four sub models namely sub model I, II, III and IV. The proposed models predicted whether pregnant women would utilize skilled delivery services or not. All sub models were developed using all input variables and derivation dataset. The performance of learning algorithms was compared based on the conventional predictive accuracy measures i.e. accuracy, area under the Receiver Operating Characteristic (ROC) curve, sensitivity and specificity [42]. The prediction performance of each class was measured separately in addition to the overall accuracy of all classes. In the contingency table, the rows represent the actual class, and the columns represent the predicted class. Each number in the contingency table is the number of records in the databases corresponding to the predicted class and the actual class [42]. It is essential to construct an interpretation of developed models [25]. Thus, interesting rules were extracted from outperforming predictive model and demonstrated using IF-THEN statements that were displayed in a decision tree.

\section{Results \\ Socio-economic and demographic characteristics of the study population}

Eleven thousand twenty-three women aged 15-49 who gave a live birth in the last five years preceding the survey were included in the study. The mean age of the mothers was $29.23(\mathrm{SD} \pm 6.54$ ), nearly $55.0 \%$ of whom were below the age of 29 . As indicated in Table 1, the majority of the respondents were rural $(89.0 \%)$ residents. More than $82 \%$ of the mothers in 
Table 1 Socio-economic and demographic characteristics of the study population in Ethiopia in $2016(n=11,023)$

\begin{tabular}{|c|c|c|c|}
\hline \multirow[t]{2}{*}{ Characteristics } & \multicolumn{2}{|c|}{ Skilled assistance during delivery } & \multirow{2}{*}{$\begin{array}{l}\text { Total } \\
\text { number } \\
\text { of births } \\
\text { (n) }\end{array}$} \\
\hline & Yes (\%) & No (\%) & \\
\hline \multicolumn{4}{|l|}{ Region } \\
\hline Tigray & 59.2 & 40.8 & 716 \\
\hline Afar & 16.5 & 83.5 & 115 \\
\hline Amhara & 27.8 & 72.2 & 2072 \\
\hline Oromia & 19.6 & 80.4 & 4850 \\
\hline Somali & 20.1 & 79.9 & 508 \\
\hline Benishangul & 28.7 & 71.3 & 122 \\
\hline SNNPR & 28.6 & 71.4 & 2296 \\
\hline Gambela & 48.1 & 51.9 & 27 \\
\hline Harari & 50.0 & 50.0 & 26 \\
\hline Addis Adaba & 96.7 & 3.3 & 244 \\
\hline Dire Dawa & 57.4 & 42.6 & 47 \\
\hline \multicolumn{4}{|l|}{ Place of residence } \\
\hline Urban & 80.1 & 19.9 & 1215 \\
\hline Rural & 21.2 & 78.8 & 9807 \\
\hline \multicolumn{4}{|l|}{ Family size } \\
\hline Five or less & 35.7 & 64.3 & 4847 \\
\hline Six and above & 21.4 & 78.6 & 6176 \\
\hline \multicolumn{4}{|l|}{ Age of mother's in years } \\
\hline $15-19$ & 38.9 & 61.1 & 378 \\
\hline $20-34$ & 29.1 & 70.9 & 7910 \\
\hline $35-49$ & 22.0 & 78.0 & 2735 \\
\hline \multicolumn{4}{|l|}{ Birth order } \\
\hline 1 & 37.0 & 63.0 & 4078 \\
\hline $2-4$ & 22.4 & 77.6 & 6878 \\
\hline $5+$ & 4.5 & 95.5 & 67 \\
\hline \multicolumn{4}{|l|}{ Current marital status } \\
\hline Never Married & 63.2 & 36.8 & 57 \\
\hline Married/Living together & 27.3 & 72.7 & 10462 \\
\hline Separated/Widowed/Divorced & 32.8 & 67.2 & 504 \\
\hline \multicolumn{4}{|l|}{ Maternal education } \\
\hline No Formal Education & 17.2 & 82.8 & 7284 \\
\hline Primary & 38.6 & 61.4 & 2951 \\
\hline Secondary and above & 83.5 & 16.5 & 788 \\
\hline \multicolumn{4}{|l|}{ Wealth status } \\
\hline Poor & 15.8 & 84.2 & 5156 \\
\hline Medium & 24.3 & 75.7 & 2280 \\
\hline Rich & 47.0 & 53.0 & 3587 \\
\hline \multicolumn{4}{|l|}{ Occupation of mother's } \\
\hline Not Working & 25.2 & 74.8 & 6127 \\
\hline Working & 30.8 & 69.2 & 4896 \\
\hline
\end{tabular}

Women's decision making on their own healthcare 
Table 1 Socio-economic and demographic characteristics of the study population in Ethiopia in 2016 ( $n=11,023)$ (Continued)

\begin{tabular}{|c|c|c|c|}
\hline \multirow[t]{2}{*}{ Characteristics } & \multicolumn{2}{|c|}{ Skilled assistance during delivery } & \multirow{2}{*}{$\begin{array}{l}\text { Total } \\
\text { number } \\
\text { of births } \\
\text { (n) }\end{array}$} \\
\hline & Yes (\%) & No (\%) & \\
\hline Independent & 35.1 & 64.9 & 1362 \\
\hline Dependent & 26.7 & 73.3 & 9661 \\
\hline \multicolumn{4}{|c|}{ First antenatal care $(n=7590)$} \\
\hline Yes & 88.79 & 11.21 & 2524 \\
\hline No & 49.21 & 50.79 & 5066 \\
\hline
\end{tabular}

the overall sample had never attended a formal education. The mean family size of the study population was $6.06(\mathrm{SD} \pm 2.19)$ persons.

Forty six percent $(46.8 \%)$ of the respondents were in the poor wealth quintile (Table 1 ). Nearly two-third, $68.8 \%(7590)$, of the respondents who had a live birth in the five years preceding the survey received first antenatal care.

\section{Determinants of skilled delivery}

In EDHS 2016, of the total 15,683 women aged 15-49 were included in the survey, 11,023 (70.2\%) of them gave at least one live birth within five years preceding the survey. Among them, only 3053 (27.7\%) proportion of the births received skilled assistance during delivery.

Table 2 presents the results of the analysis of determinants of skilled delivery. After adjusting for confounders,

Table 2 Bivariate and multivariate logistic regression for the association between independent variables and skilled delivery service utilization in Ethiopia in 2016 ( $n=11,023)$

\begin{tabular}{|c|c|c|c|c|c|}
\hline \multirow[t]{2}{*}{ Characteristics } & \multicolumn{2}{|c|}{ Skilled assistance during delivery } & \multirow{2}{*}{$\begin{array}{l}\text { Crudes } \\
\text { OR }(95 \% \mathrm{Cl})\end{array}$} & \multirow{2}{*}{$\begin{array}{l}\text { Adjusted } \\
\text { OR (95\% Cl) }\end{array}$} & \multirow[t]{2}{*}{$\overline{p \text {-value }}$} \\
\hline & Yes & No & & & \\
\hline \multicolumn{6}{|l|}{ Birth order } \\
\hline 1 & $1026(49.8 \%)$ & $1033(50.2 \%)$ & 1 & 1 & \\
\hline $2-3$ & $1042(31.0 \%)$ & $2317(69.0 \%)$ & $0.45(0.40-0.51)^{* *}$ & $0.66(0.38-1.14)^{*}$ & 0.042 \\
\hline $4-5$ & $498(19.1 \%)$ & 2108 (80.9\%) & $0.24(0.21-0.27)^{* *}$ & $0.22(0.11-0.46)^{* *}$ & 0.000 \\
\hline $6+$ & $487(16.2 \%)$ & $2514(83.8 \%)$ & $0.19(0.17-0.22)^{* *}$ & $0.39(0.17-0.91)^{*}$ & 0.030 \\
\hline \multicolumn{6}{|l|}{ Television ownership } \\
\hline Yes & $809(85.1 \%)$ & $142(14.9 \%)$ & $19.92(16.56-23.94)^{* *}$ & $6.83(2.52-18.52)^{* *}$ & 0.000 \\
\hline No & $2244(22.3 \%)$ & $7829(77.7 \%)$ & 1 & 1 & \\
\hline \multicolumn{6}{|c|}{ Cost needed for healthcare } \\
\hline Not a big problem & 1579 (37.9\%) & $2583(62.1 \%)$ & $2.24(2.05-2.43)^{* *}$ & $2.17(1.47-3.21)^{* *}$ & 0.000 \\
\hline Big problem & $1473(21.5 \%)$ & $5387(78.5 \%)$ & 1 & 1 & \\
\hline \multicolumn{6}{|l|}{ Modern family planning } \\
\hline User & $1440(41.8 \%)$ & 2009 (58.2\%) & $2.06(1.76-2.42)^{* *}$ & $1.92(1.26-2.97)^{* *}$ & 0.003 \\
\hline Non user & $1613(21.2 \%)$ & 5981 (78.8\%) & 1 & 1 & \\
\hline \multicolumn{6}{|l|}{ Age at first sex } \\
\hline 19 or below & $2317(25.2 \%)$ & $6890(74.8 \%)$ & $2.02(1.82-2.25)^{* *}$ & $2.72(1.55-4.76)^{* *}$ & 0.000 \\
\hline $20+$ & $735(40.5 \%)$ & 1080 (59.5\%) & 1 & 1 & \\
\hline \multicolumn{6}{|l|}{ Age at first birth } \\
\hline 19 or below & $1521(23.9 \%)$ & 4843 (76.1\%) & 1 & 1 & \\
\hline $20+$ & $1414(35.6 \%)$ & $2558(64.4 \%)$ & $1.76(1.61-1.92)^{* *}$ & $1.96(1.31-2.94)^{* *}$ & 0.001 \\
\hline \multicolumn{6}{|c|}{ Received first antenatal care } \\
\hline Yes & $2241(47.3 \%)$ & $2493(52.7 \%)$ & $8.17(7.13-9.35)^{* *}$ & $1.83(1.24-2.69)^{* *}$ & 0.002 \\
\hline No & $283(9.9 \%)$ & $2573(90.1 \%)$ & 1 & 1 & \\
\hline
\end{tabular}

*Statistically significant at $p$-value $<0.05$

**Statistically significant at $p$-value $<0.01$ 
higher birth order, television ownership, cost needed for healthcare, contraceptive use, age at first sex, and age at first birth, first antenatal care were significantly associated with skilled delivery service use.

Television ownership [AOR $=6.83,95 \%$ CI $(2.52-18.52)$ ] had the strongest associations with skilled delivery service use. The probability of skilled delivery service use was reduced with increasing birth order. The likelihood of skilled delivery service utilization decreased by approximately $78 \%$ in the last-born in the household compared to the firstordered child $[\mathrm{AOR}=0.22,95 \% \mathrm{CI}(0.11-0.46)]$ in the household.

Age at first sex $[\mathrm{AOR}=2.72,95 \% \mathrm{CI}(1.55-4.76)]$ was positively associated with skilled delivery service utilization, as women who had their first sex at the age of nineteen or below had almost a threefold increase in the probability of skilled delivery service utilization.

The likelihood of skilled delivery service utilization had a positive correlation with the age at first birth and women who had received first antenatal care. Women age at first birth of twenty and above had almost a twofold increase $[\mathrm{AOR}=1.96,95 \% \mathrm{CI}(1.31-2.94)]$ in the probability of skilled delivery service use compared to their counter parts.

Women who had received first ANC had almost a two-fold increase in the odds of skilled delivery service use compared to those women who never received first antenatal care $[\mathrm{AOR}=1.83,95 \% \mathrm{CI}(1.24-2.69)]$.

Women who can afford healthcare had a two-fold increase in the probability of skilled delivery service use than those who could not afford $[\mathrm{AOR}=2.17,95 \% \mathrm{CI}$ $(1.47-3.21)]$. The probability of skilled delivery service use increased with women who used contraceptives $[\mathrm{AOR}=1.92,95 \% \mathrm{CI}(1.26-2.97)]$ as compared to those who were non-users.

Those women who live in a television-equipped household were 6.83 times [AOR $=6.83,95 \% \mathrm{CI}(2.52-18.52)$ ] more likely to receive skilled assistance during delivery when compared to their counterparts.

Table 3 List of attributes ranked according to information gain attribute selection technique

\begin{tabular}{llll}
\hline Variable name & Type & Information gain score & Rank \\
\hline Television ownership & Nominal & 0.15 & 1 \\
First antenatal care & Nominal & 0.15 & 2 \\
Birth order & Nominal & 0.06 & 3 \\
Contraceptive use & Nominal & 0.05 & 4 \\
Cost needed for healthcare & Nominal & 0.04 & 5 \\
Age at first birth & Nominal & 0.02 & 6 \\
Age at first sex & Nominal & 0.01 & 7 \\
\hline
\end{tabular}

\section{Predictive modeling}

In the information gain attribute selection analysis (Table 3), television ownership, first antenatal care visit during pregnancy, and birth order were found to be the first three most important attributes in predicting skilled delivery service utilization. Thus, experiments were undertaken in order to develop a predictive model.

Among all sub-models, the model developed with $\mathrm{J} 48$ had better performance measures, accuracy, sensitivity, AUC and Positive Predictive Value (PPV) (Table 5). The model performed at an accuracy of $98 \%$. This implies that among all 14,188 instances (after SMOTE), 13,904 $(98 \%)$ were correctly classified whereas the remaining 284 (2\%), were incorrectly classified (Table 4).

Of the total 14,188 instances, the model had scored Positive Predictive Value (PPV) of $99.9 \%$ and Negative Predictive Value (NPV) of $96.1 \%$. The sensitivity and specificity of the model were 96.2 and $99.9 \%$ respectively. The areas under ROC (AUC) and F-measure were both $98.0 \%$ (Table 5).

\section{Some rules extracted from the decision tree}

Architecture of outputs from the decision tree was developed based on the outperforming sub-model I and was large and neatly visible. However, some rules extracted from the decision tree were:

1. IF a woman gives birth at a health facility and does not received first antenatal care THEN she will not receive skilled assistance during delivery.

2. IF a woman gives birth out of a health facility, receives first antenatal care, child is second or third-born, and does not have a television THEN she will not receive skilled assistance during delivery.

3. IF a woman gives birth out of a health facility, receives first antenatal care, child is second or third-born, owns a television, and had her first sex at age of 20 or above THEN she will receive skilled assistance during delivery.

4. IF a woman gives birth at a health facility, receives first antenatal care, child is second or third-born, had cost problem for healthcare, and had her first sex at age of 20 or above THEN she will not receive skilled assistance during delivery.

Table 4 Contingency table for classification of skilled delivery service utilization based on sub model II

\begin{tabular}{llll}
\hline & \multicolumn{2}{l}{ Predicted class } \\
\cline { 3 - 4 } & No skilled delivery & Yes skilled delivery \\
\hline Actual class & No-skilled -delivery & 701 & 17 \\
& Yes skilled delivery & 36 & 675 \\
\hline
\end{tabular}


Table 5 Accuracy analysis of skilled delivery prediction sub-models in Ethiopia in 2016

\begin{tabular}{|c|c|c|c|c|c|c|c|c|}
\hline Sub model & Algorithm & Accuracy & Sensitivity & Specificity & AUC & PPV & NPV & Time (in Seconds) \\
\hline I & $J 48$ & $98.0 \%$ & $96.2 \%$ & $99.9 \%$ & $98.0 \%$ & $99.9 \%$ & $96.1 \%$ & 0.09 \\
\hline$\|$ & ANN & $97.8 \%$ & $98.4 \%$ & $99.8 \%$ & $98.6 \%$ & $99.8 \%$ & $95.4 \%$ & 8.91 \\
\hline III & SVM & $97.8 \%$ & $94.8 \%$ & $99.9 \%$ & $97.8 \%$ & $99.9 \%$ & $95.5 \%$ & 15.94 \\
\hline IV & Naïve Bayes & $96.9 \%$ & $95.1 \%$ & $97.5 \%$ & $98.8 \%$ & $97.6 \%$ & $94.9 \%$ & 0.02 \\
\hline
\end{tabular}

\section{Discussion}

The present study demonstrated determinants of skilled delivery in Ethiopia using a commonly used statistical method (logistic regression) and developed a predictive model to forecast skilled delivery service use by applying machine-learning algorithms using data from a nationally representative survey in Ethiopia.

Prediction machine-learning methods are becoming popular and increasingly important in healthcare research due to their ability to handle large databases that are becoming available. This study has demonstrated relevance of machine-learning algorithms to develop prediction models based on attributes found to be determinants in multivariate logistic regression analysis.

All classification algorithms deployed in the study were substantially accurate to predict skilled delivery service use and the results were more profound [25] compared to results from commonly used statistical methods. This is because data mining algorithms reveal undiscovered relationships and interactions between attributes in the DHS data that improve the prognosis of skilled delivery use. A model developed using J48 algorithm had the highest prediction accuracy. This result indicated that J48 algorithm is the most appropriate algorithm deployed in this study to classify records of the database and make the most precise prediction. In addition, results of the 548 algorithm have the advantage of being more easily interpretable, especially when compared with closed models, called black box models, such as ANN. This advantage makes it a commonly used algorithm by the medical community [42, 43].

This study further ranked the most important attributes for predicting skilled delivery service utilization in Ethiopia which are (ordered most to least important) television ownership, first antenatal care, birth order, modern family planning, cost needed for healthcare, age at first birth, and age at first sex. Eventually, the developed predictive models at a programmatic level can help to identify the most influential determinants to promote utilization of skilled delivery services by pregnant women and thereby support evidence-based decision making in maternal health intervention programs in Ethiopia. On the other hand, at a service provider level, such models can be incorporated as a routine health service delivery tool for pregnant women in order that, based on the attributes of the pregnant woman, the service provider can identify the likelihood of a women availing skilled services at the time of delivery. In that way, the service provider can provide personalized health education and motivate the pregnant woman and her family members and the "Health Development Army (HDA)" team leaders in the Ethiopian health system that ultimately improve the use of skilled delivery services.

The study revealed that the proportion of births attended by SBA in Ethiopia in 2016 was very low, as justified in previous studies $[2,36,43]$, even compared to some low-income countries [44-46]; only $27.7 \%$ of the women received skilled assistance during delivery [20].

Birth order, first antenatal care, modern family planning, cost needed for healthcare, age at first birth, age at first sex, and television ownership were found to have significant association with skilled delivery.

Most studies in Ethiopia and other parts of the world have found a strong association between first antenatal care and skilled delivery service use [47-49]. The findings in this study corroborated that the likelihood of woman in Ethiopia receiving a skilled assistance during delivery is higher for women who have had received first antenatal care during pregnancy. This may be attributed to the fact that first antenatal care has the potential to better create awareness on the benefits of institutional delivery [50] and inform relevant knowledge about dangerous signs of pregnancy and safe delivery care $[18,24,51-54]$. On the contrary, a study conducted in Kenya reported that the use of institutional delivery services was very low even among antenatal care attendees [55].

The finding that skilled delivery service utilization is associated with deliveries conducted in health facilities is in line with the expectation and is reported by other studies $[2,24,50]$. Skilled assistance during institutional delivery is very common $[24,53]$, and studies have reported that of all skilled assistance deliveries, majority of them were conducted at health facilities [56].

These findings give credence to the differential in birth order in the likelihood of skilled delivery service utilization as well. The study results revealed that the likelihood of skilled delivery service utilization decreased with increasing birth order. This is in agreement with findings from previous studies in the same setting [56-58] and other parts of the world such as India $[24,59,60]$. The first birth is known to be more difficult [61] and a woman who had 
no experience of delivery are evidently more likely to use skilled birth attendance compared to any of the birth order categories [57] and in some settings the woman's family helps her get the best care possible [48]. On the other hand, women who had safe maternity experiences might neglect the need to have skilled assistance [60] even though very high-order births are more risky [60-62].

The study results highlight women who owned television were more likely to utilize skilled assistance during delivery as compared to those who did not own. This may be because mass media tools like television have a potential to disseminate information that geared towards promoting health-related behaviors including skilled delivery service utilization $[32,63,64]$.

Furthermore, the study found that the cost needed for healthcare was a major constraint in skilled delivery service utilization. Different studies in Ethiopia [45, 65] and across the globe have upheld similar findings. Even though, in Ethiopia, maternal health services are given free of charge by law, there is a policy practice gap in the implementation of the law [66] and mothers may not be well aware. In addition, there are hidden indirect costs such as transportation [24, 35], lodging expenses [61], and costs related to treatment at the facility $[67-71]$.

\section{Limitations of the study}

Our study utilized secondary data. Thus, authors were unable to conduct further analysis on key contexts such as maternal deaths. Authors are not privy to how low the response rate was, how cases were excluded due to poor data quality, and the how the recall bias affected the data, and thus the findings. Similar studies, following similar methodology, were scarce, as to the knowledge of the authors.

\section{Conclusions}

Birth order, first antenatal care, modern family planning, cost needed for healthcare, age at first birth, age at first sex, and television ownership were found to be determinants of skilled delivery use in Ethiopia.

Among the prediction models developed using J48, ANN, SVM, and Naïve Bayes data mining algorithms, J48 algorithm had a relatively more accurate predictive performance. The results of this study can be useful for developing a web-based application. Experimentation with other classification algorithms for skilled delivery service use as well as other maternal health services will help to develop the most accurate models.

\section{Abbreviations}

ANN: Artificial Neural Network; DHS: Demographic and Health Survey; EDHS: Ethiopian Demographic and Health Survey; ROC: Receiver Operating Characteristics; SBA: Skilled Birth Attendance; SVM: Support Vector Machine

\section{Acknowledgments}

The authors are grateful to MEASURE DHS for providing the dataset for this study. Additionally, authors are thankful to Sharaf Tariq for editing final version of the manuscript.

\section{Authors' contributions}

BT formulated problem statement, designed the study, conducted data analysis and interpretation, and prepared the manuscript. SA and TA approved the proposal and reviewed drafts of the manuscript. MK assisted with the design and analysis, and reviewed drafts of the paper. All authors read and approved the final version of the manuscript.

\section{Funding}

Not applicable.

\section{Availability of data and materials}

The data used for this study is available on MEASURE DHS website (https:// dhsprogram.com/data/) and can be accessed with permissible application.

\section{Ethics approval and consent to participate}

Institutional review board of Macro International and USAID ethically approved the data utilized on this study. Authorization to make use of the data was formally applied through an online registration on MEASURE DHS website. The study protocol was submitted. Thus, approval was sought to use the datasets.

\section{Consent for publication}

Not applicable.

\section{Competing interests}

The authors declare that they have no competing interests.

\section{Author details \\ ${ }^{1}$ World Health Organization, Kenya Country Representative Office, United Nations Office in Nairobi (UNON), Gigiri Complex, Block "U", Nairobi, Kenya. ${ }^{2}$ Department of Health Informatics, University of Ha'il, College of Public Health and Health Informatics, Hail, Kingdom of Saudi Arabia. ${ }^{3}$ Faculty of Allied Health Sciences, Institute of Public Health, University of Lahore, Lahore, Pakistan. ${ }^{4}$ John Snow Incorporated (JSI) Research and Training Institute, Arlington, VA, USA. ${ }^{5}$ Leibniz Institute for Prevention Research and Epidemiology -BIPS, Achterstraße, 30 Bremen, Germany. ${ }^{6}$ University of Bremen, Health Sciences, Bremen, Germany. ${ }^{7}$ Department of Health Informatics, University of Gondar, College of Medicine and Health Sciences, Institute of Public Health, Gondar, Ethiopia.}

Received: 15 January 2019 Accepted: 17 October 2019

Published online: 05 November 2019

References

1. Owusu PA, Asumadu-Sarkodie S. A review of renewable energy sources, sustainability issues and climate change mitigation. Cogent Engineering. 2016;3(1):1167990.

2. Shiferaw S, Spigt M, Godefrooij M, Melkamu Y, Tekie M. Why do women prefer home births in Ethiopia? BMC pregnancy and childbirth. 2013;13(1):5.

3. Hogan MC, Foreman KJ, Naghavi M, Ahn SY, Wang M, Makela SM, et al. Maternal mortality for 181 countries, 1980-2008: a systematic analysis of progress towards millennium development goal 5. Lancet. 2010;375(9726): 1609-23.

4. Keyes EB, Haile-Mariam A, Belayneh NT, Gobezie WA, Pearson L, Abdullah M, et al. Ethiopia's assessment of emergency obstetric and newborn care: setting the gold standard for national facility-based assessments. Int J Gynecol Obstet. 2011;115(1):94-100.

5. Starrs a. the safe motherhood action agenda: priorities for the next decade. Report on the safe motherhood technical consultation 18-23 October 1997 Colombo Sri Lanka 1997.

6. AbouZahr C. Global burden of maternal death and disability. Br Med Bull. 2003;67(1):1-11.

7. Khan K, Wojdyla D, Say L, Gulmezoglu A, Van Look P. WHO systematic review of causes of maternal deaths. Lancet. 2006;367(9516):1066-74.

8. Kwast BE, Liff JM. Factors associated with maternal mortality in Addis Ababa, Ethiopia. Int J Epidemiol. 1988;17(1):115-21. 
9. Ekele BA, Tunau KA. Place of delivery among women who had antenatal care in a teaching hospital. Acta Obstet Gynecol Scand. 2007;86(5):627-30

10. Agency CS. Ethiopian demographic and health survey 2005. ICF Macro: Maryland; 2006

11. Zahr CA, Wardlaw TM, Choi Y. Maternal mortality in 2000: estimates developed by WHO. UNICEF and UNFPA: World Health Organization; 2004

12. Gaym A. A review of maternal mortality at Jimma hospital, southwestern Ethiopia. Ethiop J Health Dev. 2000;14(2):215-23.

13. Moran AC, Sangli G, Dineen R, Rawlins B, Yaméogo M, Baya B. Birthpreparedness for maternal health: findings from Koupéla district, Burkina Faso. J health, population nutrition. 2006;24(4):489.

14. Villar J, Ba'aqeel H, Piaggio G, Lumbiganon P, Belizán JM, Farnot U, et al. WHO antenatal care randomised trial for the evaluation of a new model of routine antenatal care. Lancet. 2001;357(9268):1551-64.

15. Kotelchuck M. The adequacy of prenatal care utilization index: its US distribution and association with low birthweight. Am J Public Health. 1994; 84(9):1486-9.

16. McPherson RA, Khadka N, Moore JM, Sharma M. Are birth-preparedness programmes effective? Results from a field trial in Siraha district, Nepal. Journal of health, population, and nutrition. 2006;24(4):479.

17. Ransom El, Yinger NV, Sass J. Making motherhood safer: overcoming obstacles on the pathway to care; 2002.

18. CSA I. Ethiopia demographic and health survey 2011, vol. 430. Addis Ababa, Ethiopia and Calverton, Maryland: Central Statistical Agency and ICF International; 2012

19. Berhan $Y$, Berhan A. Review of maternal mortality in Ethiopia: a story of the past 30 years. Ethiop J Health Sci. 2014;24:3-14.

20. Agency CS. Ethiopian demographic and health survey 2016. ICF Macro: Maryland; 2016.

21. WHO U, UNFPA W. Maternal mortality in 2005. Geneva, Switzerland. 2007.

22. Harvey SA, Ayabaca P, Bucagu M, Djibrina S, Edson WN, Gbangbade S, et al. Skilled birth attendant competence: an initial assessment in four countries, and implications for the safe motherhood movement. Int J Gynecol Obstet. 2004;87(2):203-10.

23. Koblinsky MA, Campbell O, Heichelheim J. Organizing delivery care: what works for safe motherhood? Bull World Health Organ. 1999:77(5):399.

24. Abebe F, Berhane Y, Girma B. Factors associated with home delivery in Bahirdar, Ethiopia: a case control study. BMC research notes. 2012;5(1):653.

25. Ferreira D, Oliveira A, Freitas A. Applying data mining techniques to improve diagnosis in neonatal jaundice. BMC medical informatics and decision making. 2012;12(1):143.

26. Jay N, Nuemi G, Gadreau M, Quantin C. A data mining approach for grouping and analyzing trajectories of care using claim data: the example of breast cancer. BMC medical informatics and decision making. 2013;13(1):130.

27. Aljumah AA, Ahamad MG, Siddiqui MK. Application of data mining: diabetes health care in young and old patients. Journal of King Saud University-Computer and Information Sciences. 2013;25(2):127-36.

28. Chen $\mathrm{H}-\mathrm{Y}$, Chuang $\mathrm{C}-\mathrm{H}$, Yang $\mathrm{Y}-\mathrm{J}, \mathrm{Wu}$ T-P. Exploring the risk factors of preterm birth using data mining. Expert Syst Appl. 2011;38(5):5384-7.

29. Delen D, Walker G, Kadam A. Predicting breast cancer survivability: a comparison of three data mining methods. Artif Intell Med. 2005; 34(2):113-27.

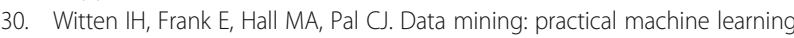
tools and techniques: Morgan Kaufmann; 2016.

31. Rutstein SO, Rojas G. Guide to DHS statistics. Calverton, MD: ORC Macro; 2006

32. Fekadu M, Regassa N. Skilled delivery care service utilization in Ethiopia: analysis of rural-urban differentials based on national demographic and health survey (DHS) data. Afr Health Sci. 2014;14(4):974-84.

33. DHS M. Standard recode manual for DHS 6. Calverton, MD: MEASURE DHS, USAID; 2013.

34. Levy PS, Lemeshow S. Sampling of populations: methods and applications: John Wiley \& Sons; 2013.

35. Tarekegn SM, Lieberman LS, Giedraitis V. Determinants of maternal health service utilization in Ethiopia: analysis of the 2011 Ethiopian demographic and health survey. BMC pregnancy and childbirth. 2014;14(1):161.

36. Tesfaye B, Atique S, Elias N, Dibaba L, Shabbir S-A, Kebede M. Determinants and development of a web-based child mortality prediction model in resource-limited settings: a data mining approach. Comput Methods Prog Biomed. 2017;140:45-51.
37. Patil TR, Sherekar S. Performance analysis of naive Bayes and $\mathbf{J 4 8}$ classification algorithm for data classification. Int J Comput Sci Appl. 2013; 6(2):256-61

38. Kuznetsov S, Obiedkov S, Roth C, editors. Reducing the representation complexity of lattice-based taxonomies. International Conference on Conceptual Structures. Kassel: Springer; 2007.

39. Jay N, Kohler F, Napoli A, editors. Analysis of social communities with iceberg and stability-based concept lattices. International Conference on Formal Concept Analysis. Kassel: Springer; 2008.

40. Zlotnik A, Alfaro MC, Pérez MCP, Gallardo-Antolín A, Martínez JMM. Building a decision support system for inpatient admission prediction with the Manchester triage system and administrative check-in variables. CIN: Computers, Informatics, Nursing. 2016;34(5):224-30.

41. Mucherino A, Papajorgji P, Pardalos PM. Data mining in agriculture: Springer Science \& Business Media; 2009.

42. Mitra S, Pal SK, Mitra P. Data mining in soft computing framework: a survey. IEEE Trans Neural Netw. 2002;13(1):3-14.

43. Teferra AS, Alemu FM, Woldeyohannes SM. Institutional delivery service utilization and associated factors among mothers who gave birth in the last 12 months in Sekela District, north west of Ethiopia: a community-based cross sectional study. BMC pregnancy and childbirth. 2012:12(1):74.

44. Mpembeni RN, Killewo JZ, Leshabari MT, Massawe SN, Jahn A, Mushi D, et al. Use pattern of maternal health services and determinants of skilled care during delivery in southern Tanzania: implications for achievement of MDG-5 targets. BMC pregnancy and childbirth. 2007;7(1):29.

45. Kruk ME, Rockers PC, Mbaruku G, Paczkowski MM, Galea S. Community and health system factors associated with facility delivery in rural Tanzania: a multilevel analysis. Health Policy. 2010;97(2-3):209-16.

46. Simkhada B, Teijlingen ERv, Porter M, Simkhada P. factors affecting the utilization of antenatal care in developing countries: systematic review of the literature. J Adv Nurs 2008;61(3):244-260.

47. Mayhew M, Hansen PM, Peters DH, Edward A, Singh LP, Dwivedi V, et al. Determinants of skilled birth attendant utilization in Afghanistan: a crosssectional study. Am J Public Health. 2008;98(10):1849-56.

48. Tsegay Y, Gebrehiwot T, Goicolea I, Edin K, Lemma H, San SM. Determinants of antenatal and delivery care utilization in Tigray region, Ethiopia: a crosssectional study. Int J Equity Health. 2013;12(1):30.

49. Regassa N. Antenatal and postnatal care service utilization in southern Ethiopia: a population-based study. African Health Sci. 2011;11(3):300-7.

50. Hagos S, Shaweno D, Assegid M, Mekonnen A, Afework MF, Ahmed S. Utilization of institutional delivery service at Wukro and Butajera districts in the northern and south Central Ethiopia. BMC pregnancy and childbirth. 2014;14(1):178.

51. Celik $Y$, Hotchkiss DR. The socio-economic determinants of maternal health care utilization in Turkey. Soc Sci Med. 2000:50(12):1797-806.

52. Ibor U, Anjorin O, Ita A, Otu M, Bassey T. Utilization of antenatal care in Ibadan north local government area, Oyo state. Nigeria Trends Med Res. 2011;6(4):273-80.

53. Raatikainen $\mathrm{K}$, Heiskanen $\mathrm{N}$, Heinonen S. Under-attending free antenatal care is associated with adverse pregnancy outcomes. BMC Public Health. 2007;7(1):268.

54. Etana B, Deressa W. Factors associated with complete immunization coverage in children aged 12-23 months in ambo Woreda, Central Ethiopia. BMC Public Health. 2012;12(1):566.

55. Ochako R, Fotso J-C, Ikamari L, Khasakhala A. Utilization of maternal health services among young women in Kenya: insights from the Kenya demographic and health survey, 2003. BMC pregnancy and childbirth 2011; 11(1):1.

56. Islam N, Islam MT, Yoshimura Y. Practices and determinants of delivery by skilled birth attendants in Bangladesh. Reprod Health. 2014;11(1):86.

57. Worku AG, Yalew AW, Afework MF. Factors affecting utilization of skilled maternal care in Northwest Ethiopia: a multilevel analysis. BMC Int Health Hum Rights. 2013;13(1):20.

58. Melaku YA, Weldearegawi B, Tesfay FH, Abera SF, Abraham L, Aregay A, et al. Poor linkages in maternal health care services-evidence on antenatal care and institutional delivery from a community-based longitudinal study in Tigray region, Ethiopia. BMC pregnancy and childbirth. 2014;14(1):418.

59. Navaneetham K, Dharmalingam A. Utilization of maternal health care services in southern India. Soc Sci Med. 2002;55(10):1849-69.

60. Stephenson R, Tsui AO. Contextual influences on reproductive health service use in Uttar Pradesh, India. Stud Fam Plan. 2002;33(4):309-20. 
61. Gabrysch S, Campbell OM. Still too far to walk: literature review of the determinants of delivery service use. BMC pregnancy and childbirth. 2009;9(1):34.

62. Elo IT. Utilization of maternal health-care services in Peru: the role of women's education. Health transition review. 1992:49-69.

63. Sachs JD. From millennium development goals to sustainable development goals. Lancet. 2012;379(9832):2206-11.

64. Van Lerberghe W. The World Health Report 2005: Make every mother and child count: World Health Organization; 2005.

65. Warren C. Care seeking for maternal health: challenges remain for poor women. Ethiopian Journal of Health Development. 2010;24(1).

66. Tibebe A, Amarech G, Melesse T, Mariam DH. Examining out of pocket payments for maternal health in rural Ethiopia: paradox of free health care un-affordability. Ethiop J Health Dev. 2012;26(1):251-7.

67. Story WT, Burgard SA, Lori JR, Taleb F, Ali NA, Hoque DE. Husbands' involvement in delivery care utilization in rural Bangladesh: a qualitative study. BMC pregnancy and childbirth. 2012;12(1):28.

68. Izugbara CO, Kabiru CW, Zulu EM. Urban poor Kenyan women and hospital-based delivery. Public Health Rep. 2009;124(4):585-9.

69. Otis KE, Brett JA. Barriers to hospital births: why do many Bolivian women give birth at home? Rev Panam Salud Publica. 2008;24:46-53.

70. Wild K, Barclay L, Kelly P, Martins N. Birth choices in Timor-Leste: a framework for understanding the use of maternal health services in low resource settings. Soc Sci Med. 2010;71(11):2038-45.

71. Mrisho M, Schellenberg JA, Mushi AK, Obrist B, Mshinda H, Tanner M, et al. Factors affecting home delivery in rural Tanzania. Tropical Med Int Health. 2007;12(7):862-72.

\section{Publisher's Note}

Springer Nature remains neutral with regard to jurisdictional claims in published maps and institutional affiliations.

Ready to submit your research? Choose BMC and benefit from:

- fast, convenient online submission

- thorough peer review by experienced researchers in your field

- rapid publication on acceptance

- support for research data, including large and complex data types

- gold Open Access which fosters wider collaboration and increased citations

- maximum visibility for your research: over $100 \mathrm{M}$ website views per year

At $\mathrm{BMC}$, research is always in progress.

Learn more biomedcentral.com/submissions 